\title{
VARIABILIDADE DO REGIME DE MONCCÕES SOBRE O BRASIL: O CLIMA PRESENTE E PROJEÇÕES PARA UM CENÁRIO COM 2XCO2 USANDO O MODELO MIROC.
}

\author{
Rodrigo José Bombardi ${ }^{1}$ e Leila Maria Véspoli de Carvalho ${ }^{2}$ \\ Depto. Ciências Atmosféricas, Universidade de São Paulo (USP). \\ Rua do Matão, 1226, SP 05508-090. \\ e-mail: bombardi@model.iag.usp.br
}

Recebido Outubro 2006 - Aceito Maio 2007

\begin{abstract}
RESUMO
Este trabalho investiga a variabilidade do Sistema de Monções da América do Sul (SMAS) sobre o Brasil com particular interesse na região do cerrado brasileiro. O início, final e total de precipitação durante as monções de verão são examinados utilizando estimativas de precipitação por satélite (pêntadas) do Global Precipitation Climatology Project (GPCP) entre 1979-2004. Analogamente, as características do regime de monção simuladas pelo modelo climático global acoplado MIROC (Model for interdisciplinary Research on Climate) do IPCC (Intergovernmental Panel for Climate Change) são examinadas em dois cenários distintos: o clima do século XX (1981-2000) e o clima em uma condição com o dobro da concentração atual de CO2 (2xCO2) na atmosfera (2061-2080). Mostra-se que a variabilidade espacial do início da monção de verão sobre o cerrado na simulação do clima do século XX pelo MIROC corresponde bem às observações. Além disso, há indicação de uma mudança das caudas da distribuição sazonal da precipitação no Cerrado para um cenário com $2 \mathrm{xCO} 2$, comparativamente com o clima presente. Este resultado sugere uma mudança na probabilidade de ocorrência de eventos extremos (secos ou úmidos) em um cenário com $2 \mathrm{xCO} 2$ sobre o cerrado, $\mathrm{o}$ que de acordo com o MIROC, indica uma maior exposição da região às consequiências de possíveis mudanças climáticas resultantes do aumento de gases de efeito estufa.
\end{abstract}

Palavras-chave: Monções, Mudanças climáticas, Cerrado, MIROC, 2xCO2, IPCC.

\begin{abstract}
VARIABILITY OF THE MONSOON REGIME OVER BRAZIL: THE PRESENT CLIMATE AND PROJECTIONS FOR A 2XCO2 SCENARIO USING THE MIROC MODEL.

This study investigates the temporal variability of the South America monsoon system (SAMS) over Brazil with focus on the Brazilian savanna. The onset, end, and total rainfall during the summer monsoon are investigated using precipitation pentad estimates from the Global Precipitation Climatology Project (1979-2004). Likewise, the variability of SAMS characteristics are investigated using the intergovernmental Panel for Climate Change (IPCC) coupled global climate model for Interdisciplinary Research (MIROC) in the 20th century (1981-2000) and in a scenario with the double present concentration of CO2 (2xCO2) (2061-2080).. It is shown that the spatial variability of the onsets over central Brazil simulated by MIROC for the 20th century run corresponds very well to the observations. Moreover, there is indication of change in the tails of the seasonal precipitation distributions over the savanna for the scenario with $2 \mathrm{xCO} 2$, comparatively to the present climate. This suggests changes in the probability of extremes (dry or wet) events over that region in a scenario with $2 \mathrm{xCO} 2$, which indicates according to MIROC the large exposure of the region to possible consequences of climate changes resulting from increasing greenhouse gases.
\end{abstract}

Key-words: Monsoon, Climate changes, Brazilian savanna, MIROC, 2xCO2, IPCC 


\section{INTRODUÇÃO}

O cerrado é a segunda maior formação vegetal brasileira. Um bioma primitivo que em sua origem cobria grande parte do centro-oeste do Brasil, parte do sudeste e estendia-se até o leste da Amazônia (Fig. 1). Nos últimos 35 anos, mais da metade dos dois milhões de $\mathrm{km}^{2}$ originais foram substituídos por plantações e pastagens, dos quais apenas 2,2 \% estão protegidos em parques ou reservas. É uma grande fonte de biodiversidade com uma fauna de 137 espécies e flora com mais de 4000 espécies (Marris, 2005). A pressão agrícola e a urbanização têm provocado crescimento econômico e social na região. Porém, este desenvolvimento tem trazido prejuízos à biodiversidade e aumentado o consumo humano e agrícola de água.

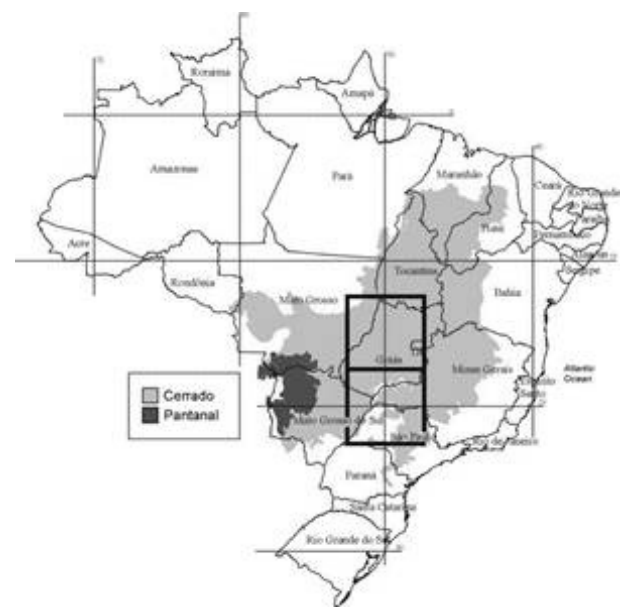

Figura 1 - Bioma cerrado. Na figura está indicada a sub-região de estudo deste trabalho, cobrindo o domínio $12,5^{\circ}-22,5^{\circ} \mathrm{S}$ e $47,5^{\circ}$ $52,5^{\circ} \mathrm{W}$.

Aliados a estes aspectos regionais, mudanças climáticas forçadas pelo aquecimento global oriundo do aumento de $\mathrm{CO} 2$ do último século (IPCC-2001) podem apresentar conseqüências ainda desconhecidas, alterando o regime de precipitação e seus extremos. Por exemplo, na América do Sul (AS), os fatores considerados como mais importantes dentre os vários que podem sofrer impactos devido à mudança do clima estão os recursos hídricos, ecossistemas, agricultura, aumento do nível do mar e saúde (IPCC, 2001). A mudança no uso da terra é o principal fator relacionado às mudanças nos ecossistemas da AS (IPCC, 2001).

Vera et al (2006) analisaram sete modelos climáticos do IPCC e verificaram um aumento significativo na precipitação durante o trimestre Janeiro a Março para a região sudeste da AS e norte dos Andes e diminuição da precipitação no sul dos Andes. Meehl et al (2005) analisaram as saídas de nove modelos climáticos para final do século XXI e verificaram que a maioria das regiões mostra aumento da intensidade da precipitação para a média dos modelos, sendo que a América do Sul é uma das regiões que apresentam as maiores diferenças. A elevação da temperatura da superfície do mar na região tropical leva a um aumento na evaporação enquanto que temperatura elevadas na atmosfera aumentam a capacidade do ar em reter água. Estes fatores levam a um aumento da convergência de umidade no ar e conseqüentemente a um aumento da precipitação média (Meehl et al, 2005).

Uma importante característica do clima da AS tropical é a presença de um regime de monções. A idéia da existência de um regime de monções na América do Sul é relativamente recente. O termo monção freqüentemente indica uma reversão sazonal na circulação de grande escala, causada pelo aquecimento diferencial entre continentes e oceanos. Baseados no padrão sazonal de várias características da circulação atmosférica, Zhou e Lau (1998) demonstraram que a estação de verão na AS contém os principais padrões para ser caracterizada como um regime de monções. Embora a circulação de leste prevaleça no Atlântico tropical e no norte da AS durante todo o ano, quando a média anual é removida da composição de verão e inverno, as características de mudanças nas anomalias mensais de ventos em baixos níveis tornam-se evidentes. $\mathrm{O}$ início das monções de verão da AS é caracterizado pela formação de convecção sobre o noroeste da região Amazônica que se estende em seguida na direção sudeste da AS, intensificando-se progressivamente (Kousky 1988, Marengo et al. 2001, Gan et al. 2004 e Vera et al, 2006). Na maior parte da região central e sudeste do Brasil a estação chuvosa pode se iniciar entre setembro e novembro e terminar entre março e abril (p.ex., Gan et al. 2004).

A Zona de Convergência do Atlântico Sul (ZCAS), caracterizada por uma banda de precipitação e nebulosidade que se estende desde a Amazônia até o sudeste do Brasil em direção ao oceano Atlântico, é parte intrínseca ao regime de monções da AS e, portanto, possui papel fundamental para a variabilidade e qualidade da estação chuvosa durante o verão sobre o sudeste e centro-oeste do Brasil (Carvalho et al. 2002; Carvalho et al. 2004). A grande variabilidade de escalas temporais e espaciais existentes é uma característica marcante do regime de monções na AS (Kayano e Kousky 1992; Lenters e Cook, 1998; Grimm et al, 1998; Jones e Carvalho 2002; Carvalho et al. 2002; Vera et al, 2006).

O objetivo do presente estudo está em caracterizar a variabilidade espacial e inter-anual do início e término das monções de verão sobre o Brasil tropical, bem como dos totais de precipitação observados. Além disso, pretende-se avaliar o comportamento destas características num cenário futuro de mudanças globais, utilizando o modelo climático MIROC. Com esta abordagem, este trabalho tem o propósito de contribuir para o prognóstico de condições climáticas sobre o cerrado brasileiro, 
uma vez que o início, fim e duração da estação chuvosa e a regularidade das chuvas na região têm um papel importante para a manutenção do bioma.

\section{MATERIAL E MÉTODOS}

\subsection{Dados}

Neste estudo, utilizam-se dados de precipitação em pêntadas construídas pelo Global Precipitation Climatology Project (GPCP). Estes dados de precipitação consistem em estimativas de satélite e medidas de estações de superfície (Xie et al. 2003). Os dados do GPCP possuem resolução de $2,5^{\circ}$ de latitude/longitude e abrangem latitudinalmente de $60^{\circ} \mathrm{S}$ a $60^{\circ} \mathrm{N}$ e longitudinalmente todo o globo. O período considerado é de 1979 a 2004. Saídas do modelo japonês acoplado MIROC3.2hires (Model for Interdisciplinary Research On Climate; Hasumi e Emori, 2004) são examinadas para dois cenários distintos: o clima do século XX (1981-2000) e o clima numa condição

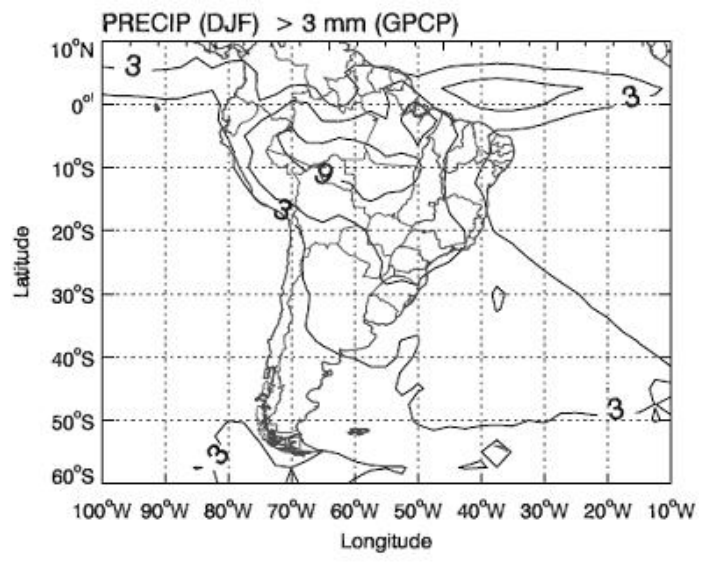

a)

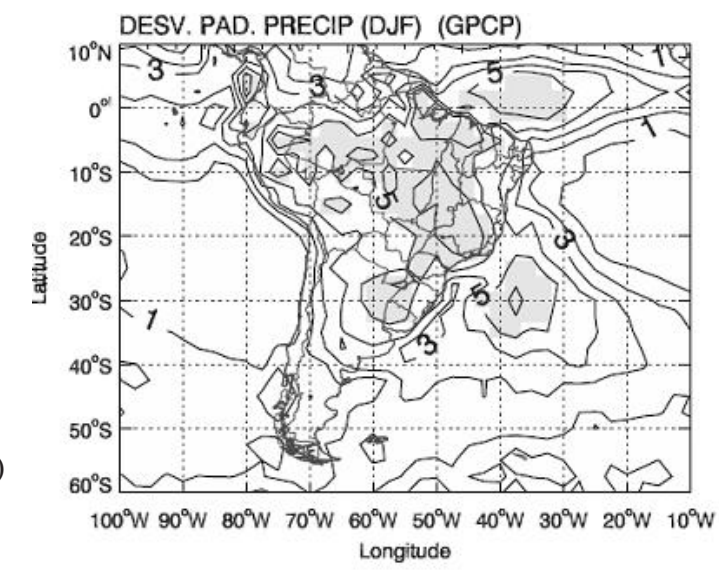

com o dobro da concentração atual de CO2 na atmosfera (20612080). Estas são disponibilizadas pelo Intergovernmental Panel for Climate Change (IPCC) efetuadas com o propósito de se conhecer a habilidade dos modelos em simular o clima do século XX e suas variabilidades de acordo com alguns possíveis cenários futuros.

O MIROC foi examinado neste trabalho porque é um dos modelos acoplados do IPCC que simula de modo realista a posição e intensidade da ZCAS (Vera et al, 2006). Além disso, a simulação do MIROC para o século XX apresenta precipitação média diária para o trimestre de Dezembro a Fevereiro de $9 \mathrm{~mm}$ sobre a região central do Brasil e sul da Amazônia, consistentes com a climatologia obtida pelo GPCP (Fig. 2.a,b). As características da variabilidade da precipitação simuladas pelo MIROC e indicadas pelo desvio padrão do trimestre Dezembro a Fevereiro (Fig.2) também são semelhantes ao observado com a climatologia do GPCP, com destaque sobre o máximo observado sobre o Atlântico em associação com a ZCAS (Carvalho et al. 2002).

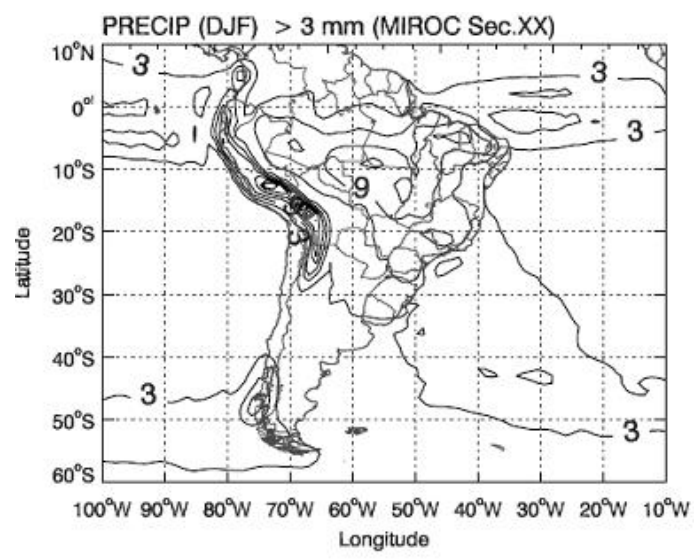

b)

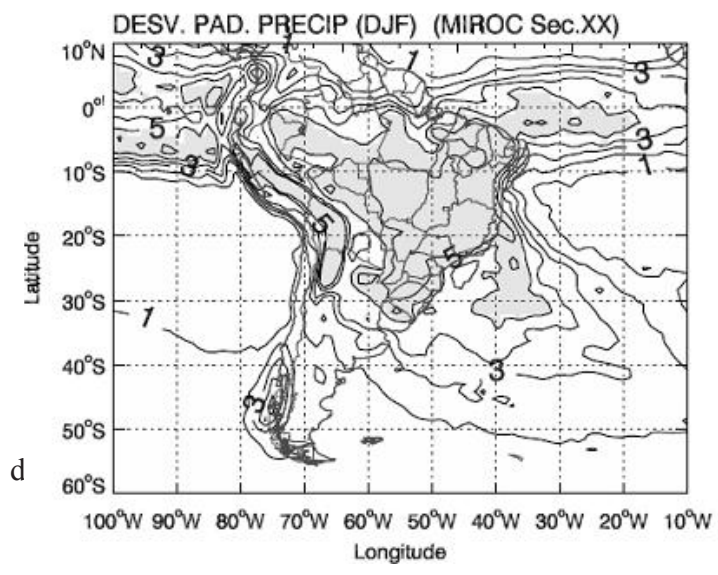

Figura 2 - Precipitação média diária para o trimestre de Dezembro a Fevereiro, representada pelo (a) GPCP e (b) modelo para cenário do século XX. As figuras mostram apenas os valores das regiões onde a precipitação média diária, de cada conjunto de dados, está acima de 3 mm/dia. As isolinhas estão espaçadas de $3 \mathrm{~mm}$. Desvio padrão da média diária da precipitação, para o trimestre de Dezembro a Fevereiro, representado pelo (c) GPCP e (d) modelo para cenário do século XX. O intervalo de isolinhas começa em $1 \mathrm{~mm}$ e estão espaçadas de $1 \mathrm{~mm}$. A região sombreada indica que o desvio padrão é igual ou superior a $5 \mathrm{~mm}$. 
O MIROC é um modelo de circulação geral acoplado com resolução horizontal espectral T106, que é equivalente a aproximadamente à resolução de $1,125^{\circ}$ de latitude/longitude, 56 níveis verticais em coordenada $\mathrm{s}$, com grande resolução vertical na camada limite planetária e na tropopausa. Consiste de cinco modelos componentes: atmosfera, continente, rios, gelo do mar e oceano. A componente atmosférica interage com as componentes continente e gelo. As trocas entre o oceano e a atmosfera ocorrem exclusivamente entre a atmosfera e o gelo, e não entre a atmosfera e o oceano diretamente, sendo que a componente oceânica interage unicamente com o gelo. Ou seja, o fluxo armar em áreas sem cobertura de gelo passa para a componente oceânica sem modificação, mas passa primeiro pela componente de gelo marinho. Isto não implica que a componente oceano não force a atmosfera. A componente rio recebe o escoamento da água dos continentes e fornece água para a componente gelo do mar (Hasumi e Emori, 2004). As parametrizações da componente atmosférica compreendem convecção de cumulus (Arakawa e Schubert, 1974), condensação de grande escala (baseado no esquema de Le Treut e Li, 1991), transferência radiativa (Nakajima et al, 2000), fluxos de superfície, difusão vertical (Mellor e Yamada, 1974, 1982) e ondas de gravidade internas (McFarlane, 1987).

Foram utilizadas as integrações totalmente acopladas (fully coupled), tanto para a simulação do século XX quanto para a integração $2 \mathrm{CO} 2$, onde ambas são inicializadas com uma integração controle "pré-industrial" com 109 anos de estabilização (spin up). A simulação do cenário século XX foi integrada por 101 anos $(1900-2000)$ e foram utilizados os últimos 20 anos. A simulação $2 \mathrm{xCO} 2$ foi integrada por 80 anos (não contados o período de estabilização do modelo) onde a concentração de $\mathrm{CO} 2$ foi aumentada de $1 \%$ ao ano até que atingisse o dobro da concentração atual na atmosfera. Foram utilizados os últimos 20 anos de integração sendo 10 anos posteriores e 10 anos anteriores à data em que o dobro da concentração atual de $\mathrm{CO} 2$ na atmosfera é atingido (detalhes sobre as simulações do modelo MIROC podem ser vistos em http://www-pcmdi.llnl.gov/ipcc/model_documentation/ MIROC3.2_hires.htm). Os dados da simulação do século XX foram degradados para uma grade de $2.5^{\circ}$ latitude/longitude com a finalidade de comparar com os dados observados.

Neste trabalho, enfoque particular será dado para a região do cerrado brasileiro que compreende aproximadamente o domínio entre 22,5S - 12,5S e 47,5W - 52,5W. Esta região foi subdividida em dois subdomínios correspondentes ao setor sudoeste da região sudoeste (SE) $(17,5 \mathrm{~S}-12,5 \mathrm{~S}$ e $47,5 \mathrm{~W}$ $-52,5 \mathrm{~W})$ e ao setor sudeste da região Centro-Oeste (CO) $(22,5$ $\mathrm{S}-17,5 \mathrm{~S}$ e 47,5 W-52,5W) do Brasil, conforme indicado na Fig. 1. A investigação em subdomínios distintos tem o propósito de examinar em detalhes a região de transição do cerrado com outros biomas do sul do Brasil, os quais estão igualmente sujeitos a um regime de precipitação diferenciado, como será discutido adiante.

\subsection{Caracterização da estação chuvosa}

O início, o fim e, conseqüentemente, a duração da estação chuvosa foram determinados utilizando somente dados de precipitação. Para isso, o método proposto por Liebmann e Marengo (2001) foi adaptado, tal que:

$$
S(\text { pentada })=\sum_{n=\text { pentad } a_{0}}^{\text {pentada }}(R(n)-\bar{R})
$$

Onde $\mathrm{R}($ n) é a precipitação medida na pêntada $\mathrm{n}, \bar{R}$ é a precipitação média anual climatológica (tomados as 73 pêntadas). Para se determinar o início da estação chuvosa, calcula-se a somatória S (linha cheia - Fig. 3) para cada pêntada do ano, iniciando na estação seca de um determinado ano e terminando na estação seca do ano seguinte.

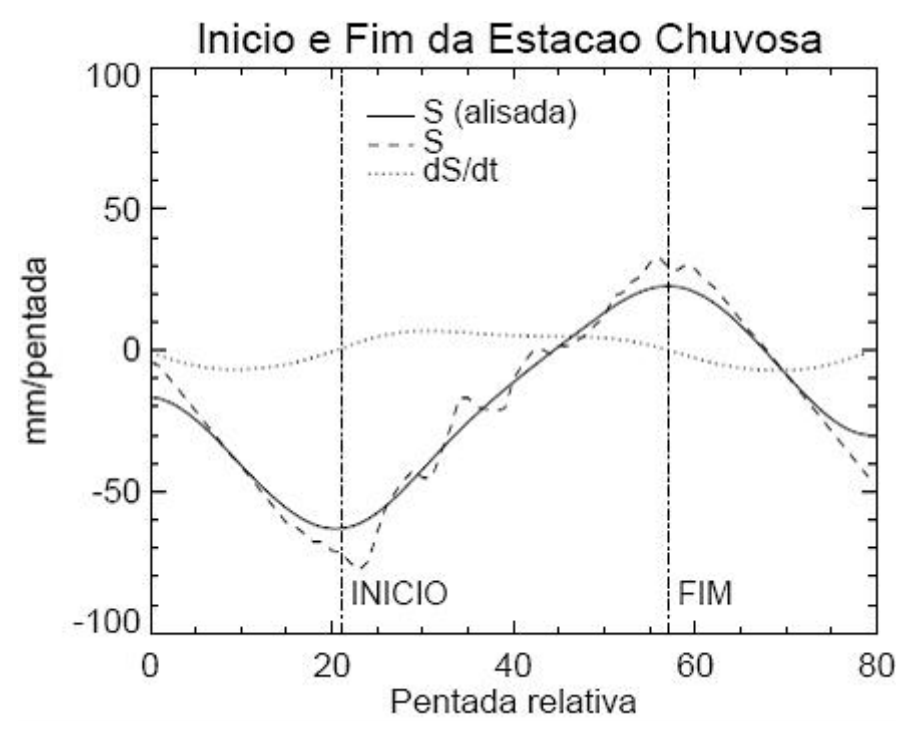

Figura 3 - Exemplo de aplicação do método adaptado de Liebmann e Marengo (2001) para a determinação do início e fim da estação chuvosa. A linha tracejada indica a estimativa de S (Eq. 1); a linha contínua indica a estimativa 'alisada' de S (média móvel 3 pontos e 40 passadas) e a linha pontilhada indica a derivada de $\mathrm{S}$ alisada. As curvas estão representadas em função do tempo a partir da pêntada inicial (pentada0) e a ordenada representa a anomalia de precipitação acumulada (mm/pêntada). A taxa de variação de $\mathrm{S}(\mathrm{dS} / \mathrm{dt})$ é utilizada para determinar o início $(\mathrm{dS} / \mathrm{dt}>0)$ e final $(\mathrm{dS} / \mathrm{dt}<0)$ da estação chuvosa (vide texto). 
A primeira pêntada (pêntadao) desta somatória deve ser tomada bem dentro da estação seca para que não seja perdido o início da estação chuvosa (Liebmann e Marengo 2001). No presente trabalho, a pêntada0 foi escolhida como sendo a pêntada em que o ciclo anual médio da precipitação para aquele ponto de grade apresenta seu mínimo. Para cada ano, a somatória $\mathrm{S}$ (Eq. 1) foi calculada a partir da pêntada0 até cinco pêntadas após a pentada0 do ano seguinte. S(pêntada) foi suavizada aplicando-se uma média-móvel de três pontos, passada 40 vezes (linha tracejada - Fig.3). Inicialmente, a somatória $\mathrm{S}$ terá contribuições negativas. $\mathrm{O}$ momento em que $\mathrm{S}$ passa a ter contribuições positivas, após apresentar um ponto de mínimo na curva $\mathrm{S}$ (pêntada) (isto é, dS/dt >0) (Fig. 3), é considerado o início da estação chuvosa. Analogamente, tomando-se a pêntadao bem dentro da estação chuvosa, determina-se o fim desta quando a somatória $\mathrm{S}$, antes positiva, passa a ter contribuições negativas $(\mathrm{dS} / \mathrm{dt}<0)$.

A análise da variabilidade interanual do início, duração e total precipitado dentro da estação chuvosa foi baseada na análise de quartis, utilizando a mediana como medida de comparação entre os dados observados e simulados pelo MIROC. A média representa a posição central de uma distribuição normal e pode não ser a opção mais adequada principalmente se a distribuição for bi-modal ou apresentar assimetria (p.ex., com uma das extremidades mais alongada). Como a distribuição de freqüência das variáveis é desconhecida, optou-se por utilizar a mediana ao invés da média por ser a mediana uma medida menos sujeita à influência de extremos (Wilks, 2006).

\section{RESULTADOS E DISCUSSÃO}

\subsection{Precipitação durante a estação chuvosa.}

As medianas do total precipitado durante a estação chuvosa para os dados do GPCP estão apresentadas na fig. 4a. Percebe-se que os maiores totais encontram-se sobre a região Amazônica brasileira, com valores por volta de $1600 \mathrm{~mm}$ no sul, leste e centro e $1400 \mathrm{~mm}$ no oeste. Um máximo sobre a região da foz do Amazonas também é observado. Estes resultados são, em parte, coerentes com os obtidos por Marengo et al (2001) e Liebmann e Marengo (2001) nos quais o nordeste da Amazônia e a região da foz do rio Amazonas apresentaram os maiores valores de total precipitado anual. Liebmann e Marengo (2001) utilizaram dados de pluviômetros e notaram que a precipitação anual média na região varia mais de $50 \%$ dentro da Bacia Amazônica, passando de menos que $2000 \mathrm{~mm}$ no sul, leste e extremo norte a mais que $3000 \mathrm{~mm}$ no noroeste, onde começam a ocorrer levantamentos orográficos. Notaram, também, um máximo secundário próximo à foz do rio Amazonas que associaram à convergência noturna dos alíseos com a brisa terrestre. Sobre a região do cerrado brasileiro a precipitação é relativamente menor, com medianas entre 1000 a $1400 \mathrm{~mm}$.

O modelo MIROC consegue reproduzir para a simulação do século XX alguns padrões observados, porém algumas vezes falha na distribuição espacial (Fig. 4b). Por exemplo, a região com um máximo de precipitação observada sobre a região norte da Amazônia e da foz do Amazonas foram subestimadas em mais de $120 \mathrm{~mm}$ pelo modelo, enquanto sobre o norte da região Nordeste do Brasil a precipitação foi superestimada em aproximadamente $40 \mathrm{~mm}$, o que consiste em uma diferença importante, pois indica uma falha do modelo em representar de forma realista padrões da distribuição espacial da precipitação sobre a Amazônia provavelmente associada com a Zona de Convergência Inter-Tropical (ZCIT). Sobre a região do cerrado a precipitação é subestimada sobre os estados do Mato Grosso e Mato Grosso do Sul e superestimada sobre a região que engloba Tocantins, Goiás, Minas Gerais e São Paulo, chegando a diferenças de aproximadamente $20 \mathrm{~mm}$.

Além disso, as diferenças na maior parte da região do cerrado são pequenas e não são estatisticamente significativas para o teste da mediana, o que indica que a representação da precipitação sazonal de verão pelo modelo MIROC para o cenário do século XX correspondeu parcialmente ao esperado (Fig. 4b). A região com valores altos a oeste da AS na figura $4 \mathrm{~b}$ deve-se a um problema de topografia, no caso a presença da cordilheira dos Andes. Os modelos globais em geral tendem a superestimar a precipitação quando há uma topografia muito acentuada (Marengo et al, 2003).

\subsection{Início e duração da estação chuvosa.}

Os dados do GPCP indicam que a mediana de início da estação chuvosa encontra-se por volta do final de outubro (pêntada 60) sobre a foz do Amazonas, sul e oeste da Amazônia. Grande variação no início da estação chuvosa é observada no noroeste da região (Fig. 5a), o que é consistente com Liebmann e Marengo (2001). O início da estação chuvosa mostra uma progressão de norte para sul. Isto se deve ao ciclo das monções de verão do Hemisfério Sul, onde a convecção forma-se sobre o noroeste da região Amazônica e em seguida estende-se para o sudeste da AS, intensificando-se progressivamente (Kousky 1988, Marengo et al. 2001 e Gan et al. 2004, Vera et al, 2006). O Centro-Oeste e Sudeste do Brasil apresentam medianas de início da estação chuvosa entre as pêntadas de 56 a 60 (início de outubro a início de novembro) (Fig. 5a). Porém, o início da estação chuvosa sobre estas regiões não parece ser tão bem organizado. Há uma grande variabilidade espacial no início da regularidade das chuvas (Lincoln et al, 2005) de forma que 


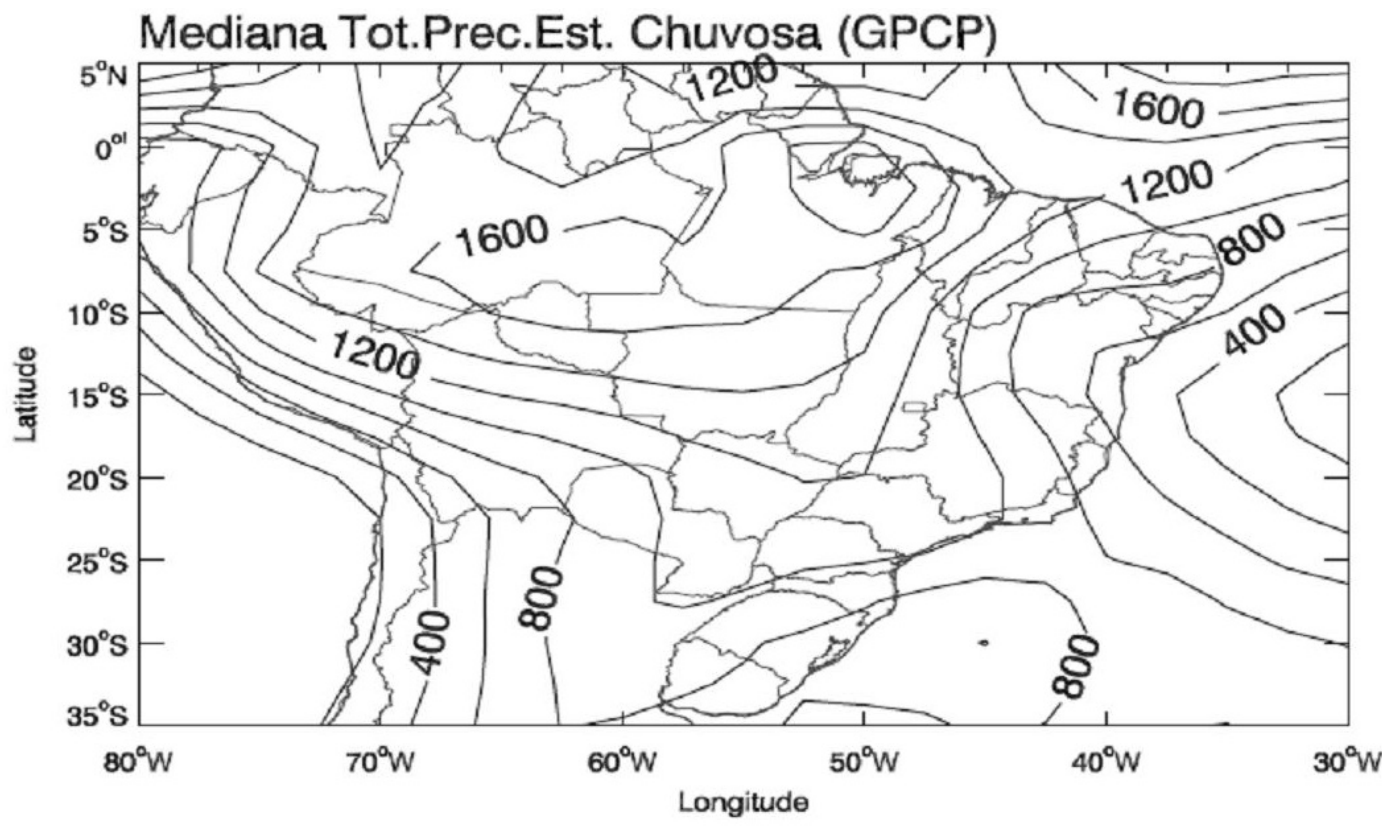

a)

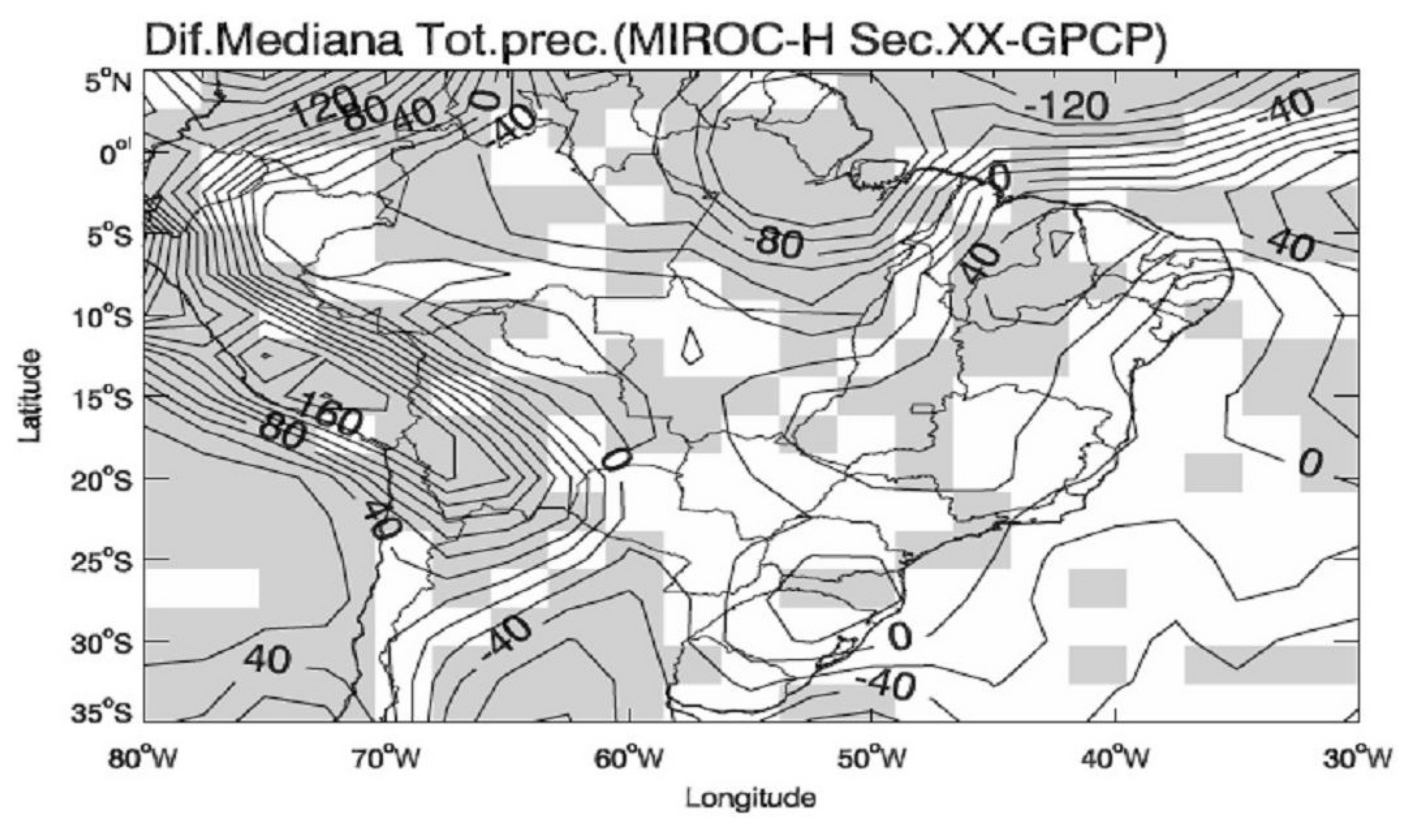

b)

Figura 4 - (a) Mediana do total precipitado durante a estação chuvosa de acordo com GPCP, onde as isolinhas estão separadas por um intervalo de $200 \mathrm{~mm}$; (b) diferença entre a mediana do total precipitado durante a estação chuvosa simulada pelo MIROC para o cenário do século XX e a mediana do total precipitado durante a estação chuvosa de acordo com GPCP, onde as isolinhas estão separadas por um intervalo de 20 mm e as regiões sombreadas mostram as regiões onde a diferença é estatisticamente significativa para o teste da mediana, ao nível de significância de 5 \%. 
regiões mais ao norte como Tocantins e Mato Grosso podem experimentar um início atrasado da estação chuvosa em relação ao sudeste do Brasil (Fig. 5a).
O litoral do Nordeste brasileiro, Sul do Brasil, Uruguai e algumas regiões do Norte do Brasil apresentam os valores mais baixos para as medianas de início da estação chuvosa (Fig. 5a).

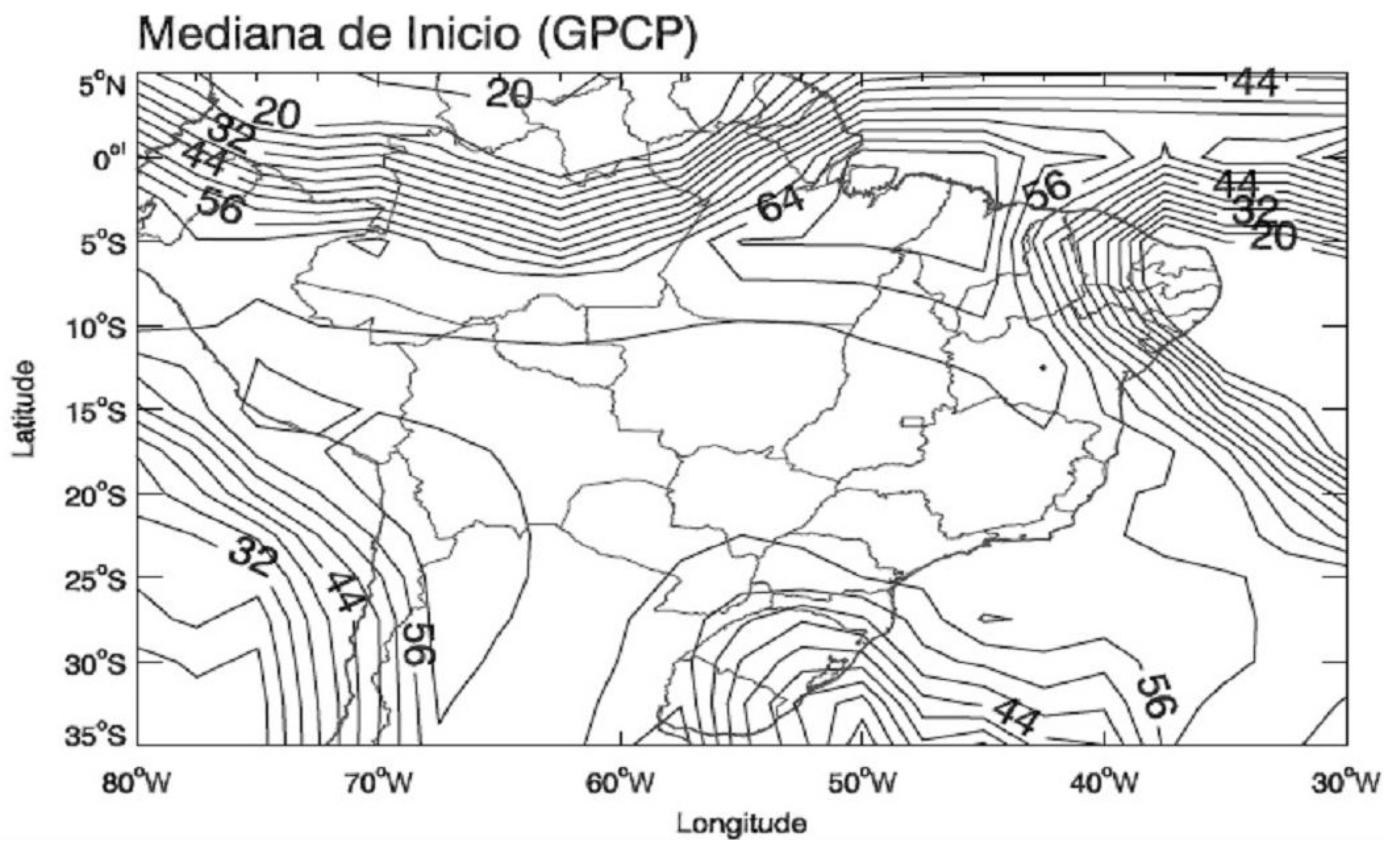

a)

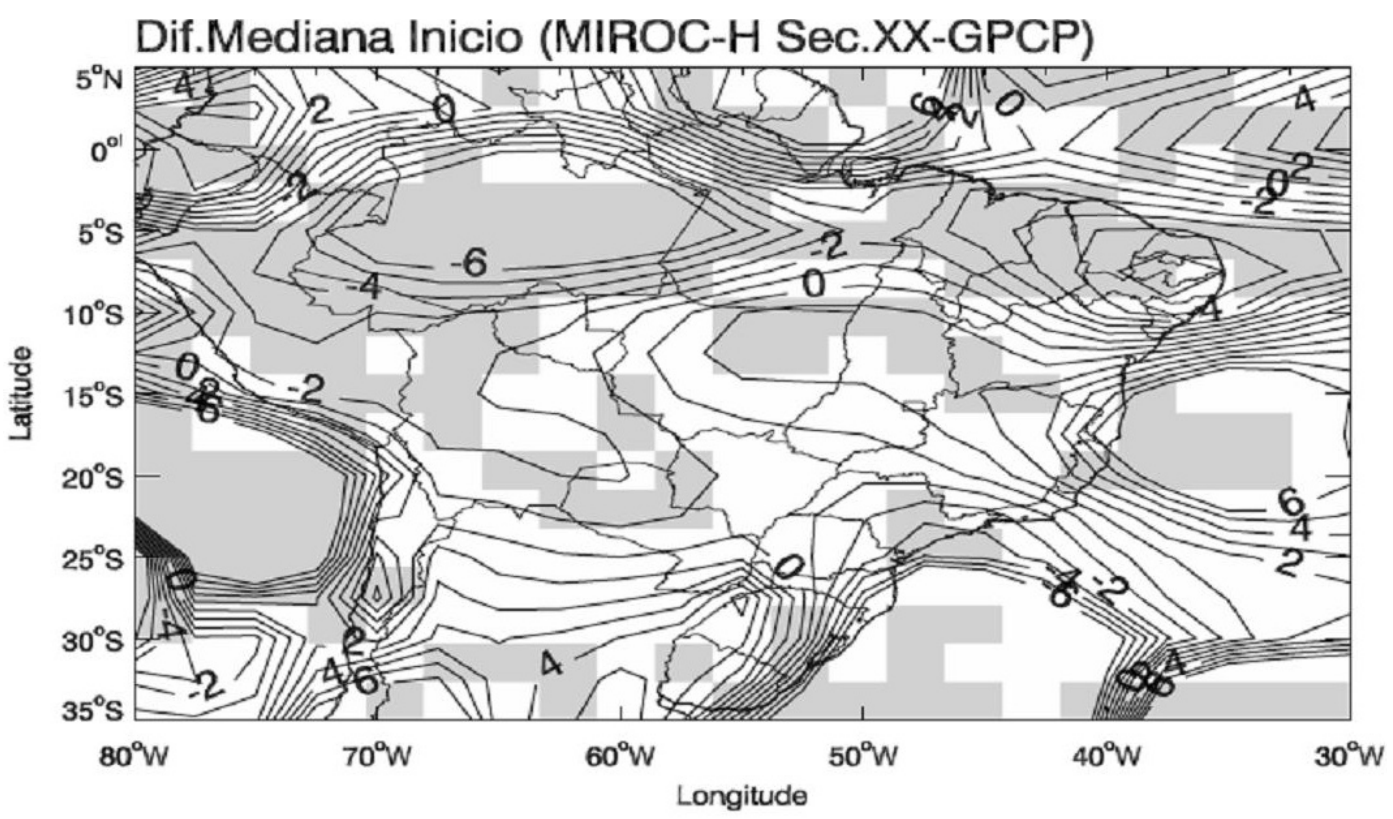

b)

Figura 5 - (a) mediana do início da estação chuvosa de acordo com o GPCP, onde as isolinhas estão separadas por um intervalo de 4 pêntadas; (b) diferença entre a mediana do início da estação chuvosa simulada pelo MIROC para o cenário do século XX e a mediana do início da estação chuvosa de acordo com GPCP, onde as isolinhas estão separadas por um intervalo de 1 pêntada e as regiões sombreadas mostram as regiões onde a diferença é estatisticamente significativa para o teste da mediana, ao nível de significância de $5 \%$. 
Estes resultados são esperados, uma vez que o norte da região Nordeste do Brasil a estação chuvosa ocorre de fevereiro a maio e no leste da região a estação chuvosa é de abril a julho (Rao et al, 1993; Yamazaki e Rao, 1977).

Além disso, o sudoeste e nordeste do Rio Grande do Sul apresentam um ciclo anual bi-modal de precipitação (Grimm et al. 1998), o qual se deve possivelmente à interferência de dois regimes: as monções de verão e a maior ocorrência de sistemas frontais durante o inverno (Grimm et al. 1998; Grimm et al. 2000). a)

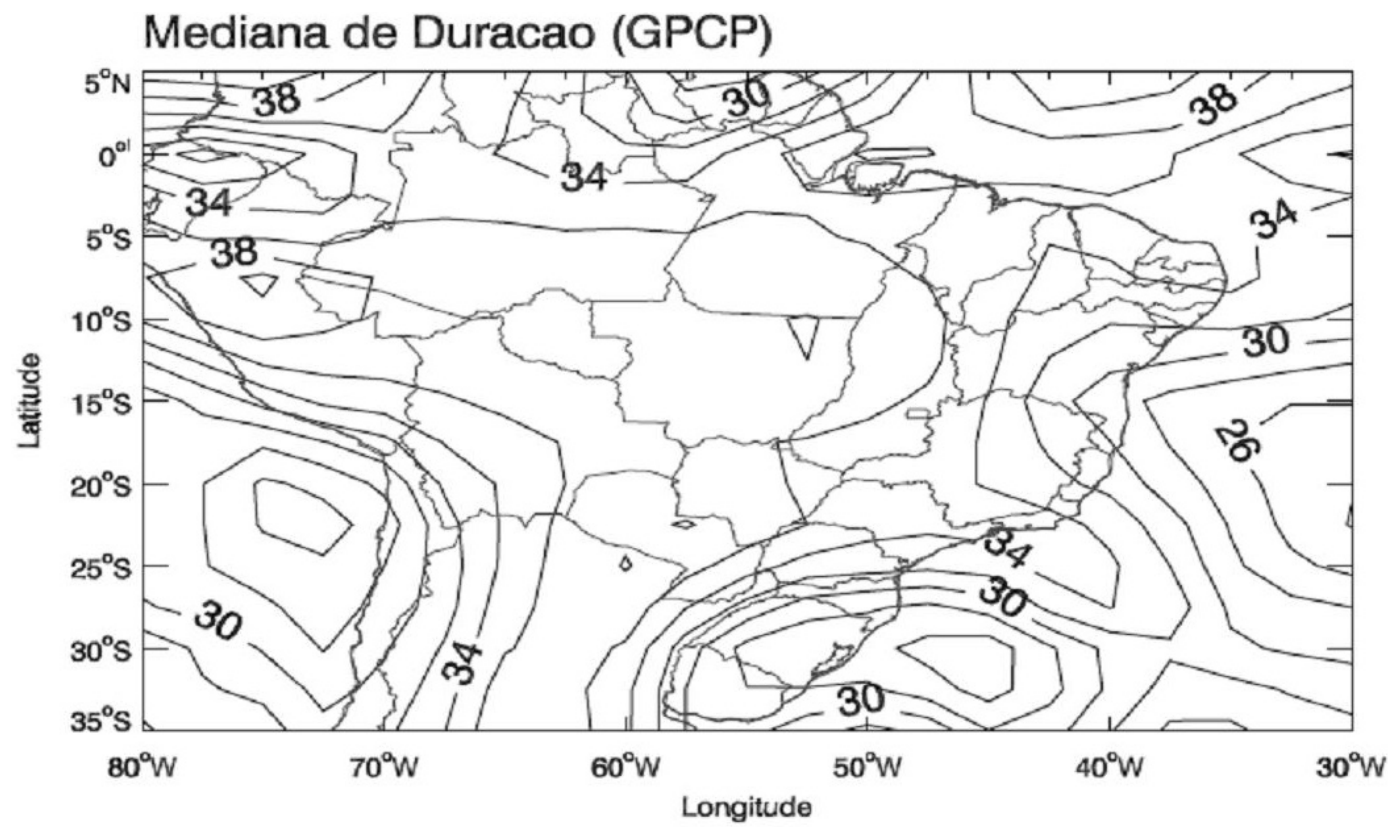

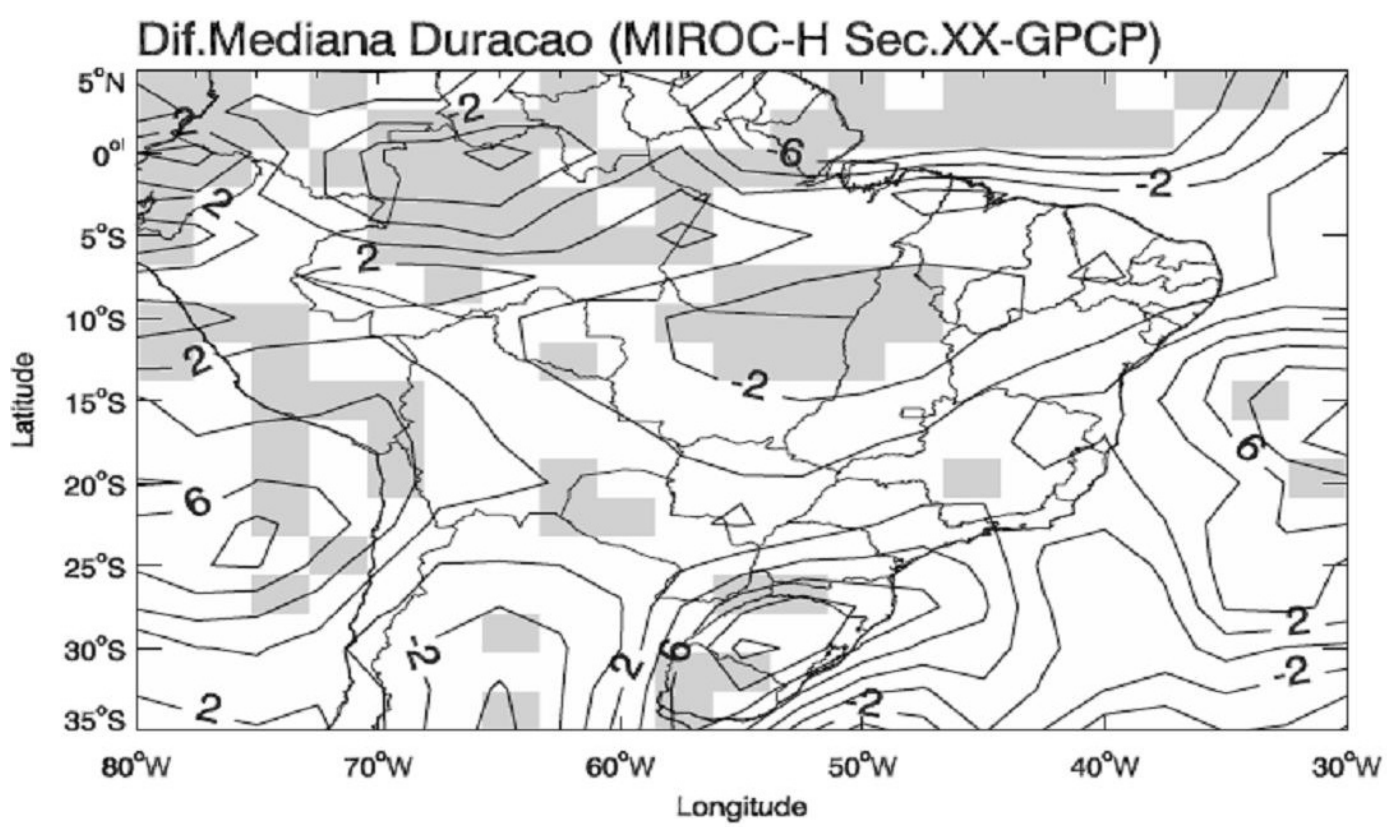

Figura 6 - (a) mediana da duração da estação chuvosa de acordo com o GPCP, onde as isolinhas estão separadas por um intervalo de 2 pêntadas; (b) diferença entre a mediana da duração da estação chuvosa simulada pelo MIROC para o cenário do século XX e a mediana da duração da estação chuvosa de acordo com GPCP, onde as isolinhas estão separadas por um intervalo de 2 pêntadas e as regiões sombreadas mostram as regiões onde a diferença é estatisticamente significativa para o teste da mediana, ao nível de significância de $5 \%$. 
Sobre grande parte do Brasil central, O MIROC consegue reproduzir as características de início da estação chuvosa para o clima do século XX similarmente ao observado, apresentando diferenças de no máximo duas pêntadas em relação aos dados do GPCP (Fig. 5b). A mediana de início da estação chuvosa sobre o cerrado não apresenta diferença estatisticamente significativa sobre a maior parte da região, o que indica que a posição central dos dois conjuntos de dados é estatisticamente semelhante. As principais diferenças ocorrem sobre o Nordeste do Brasil, Amazônia e extremo sul do país (Fig. 5b), com início antecipado da estação chuvosa sobre a região Nordeste do Brasil, centro-oeste da Amazônia e na costa do sul do Brasil e início antecipado sobre a região da foz do rio Amazonas e no leste do Rio Grande do Sul, chegando a diferenças de mais de Seis pêntadas (30 dias) (Fig. 5b).A mediana de duração da estação chuvosa observada com os dados do GPCP varia entre 32 e 36 pêntadas na maior parte da AS (fig. 6a), com maiores valores no interior do continente. Kousky (1988) utilizou um critério para caracterização da estação chuvosa baseado em dados de radiação de onda longa emergente (ROLE) e verificou uma tendência a estações chuvosas mais duradouras a partir do sudeste do Brasil em direção ao noroeste até o oeste da Bacia Amazônica. O mesmo pode ser observado aqui, porém próximo ao sudoeste da Bacia Amazônica em direção noroeste a duração

Correlacao Tot.Prec.e Duracao (GPCP)

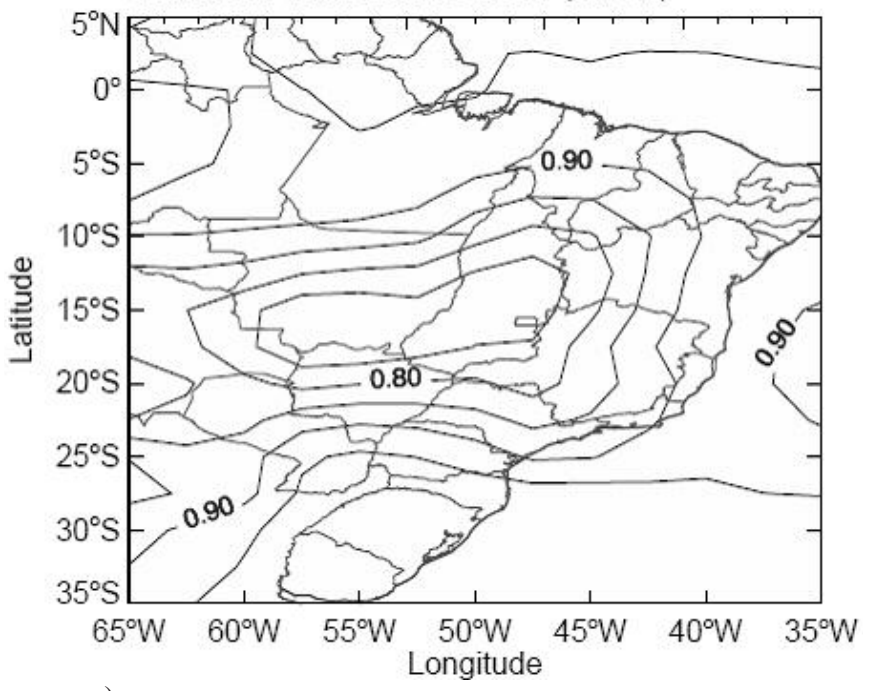

a) da estação chuvosa passa a diminuir. A simulação do clima do século XX pelo MIROC sobre o Brasil central subestima a mediana de duração da estação chuvosa em até duas pêntadas, representando um mínimo sobre o nordeste do Mato Grosso, Tocantins e sul do Pará (fig. 6b).

A correlação entre a duração e o total precipitado durante a estação chuvosa está indicada na Fig. 7. Altas correlações são observadas em todo o domínio estudado para os dados do GPCP, com valores acima de 0.90 no extremo norte e no sul do Brasil (Fig. 7a). A correlação vai diminuindo em direção ao Brasil central, ficando entre 0,85 e 0,75 na região do cerrado. A diminuição dos valores de correlação sobre o cerrado sugere que a precipitação sobre esta região não é uniforme durante a estação chuvosa. Períodos longos de seca e/ou chuva forte podem ocorrer independentemente da duração da estação e podem ser causados por distúrbios em escala intra-sazonal (e.g. Carvalho et al. 2004).

O padrão de correlação nas simulações do modelo MIROC para século XX é semelhante ao que foi observado pelo GPCP, tanto em intensidade quanto em distribuição espacial (Fig. 7b). A diminuição da correlação linear entre a duração da estação chuvosa e o total precipitado no Brasil central (0.80) sugere que a chuva simulada para esta região pode apresentar variância espectral em escala inter-anual (por exemplo, resposta às forçantes de temperatura à superfície do mar) como também sub-sazonal. Lin et al. (2006) examinaram diversos modelos acoplados do IPCC e mostraram que o MIROC apresenta

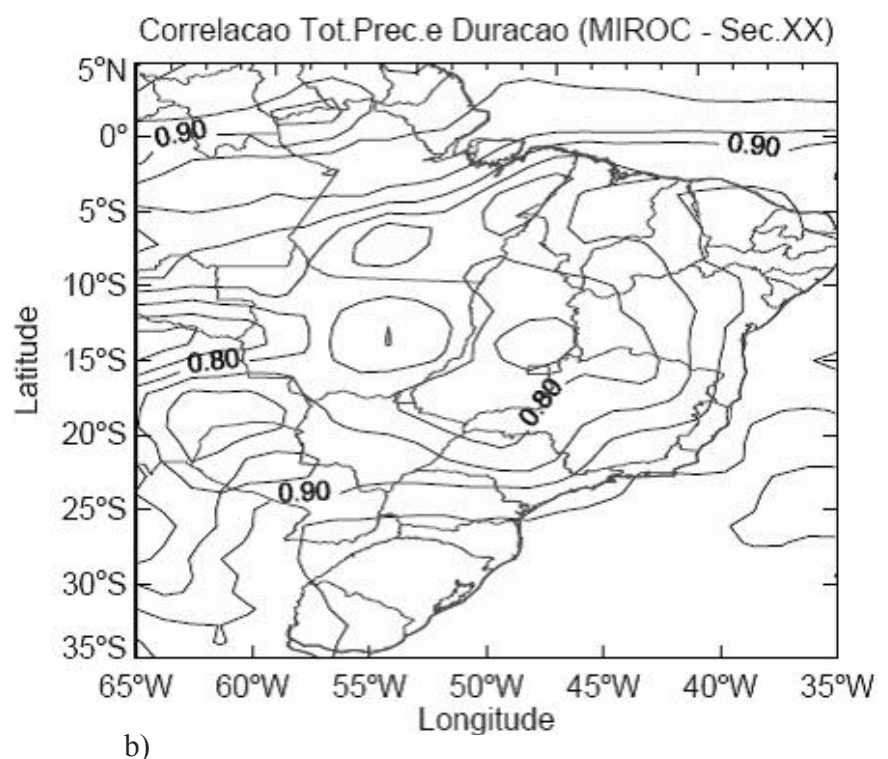

Figura 7 - Correlação entre o total precipitado durante a estação chuvosa e a duração, para os dados do (a) GPCP; (b) modelo MIROC simulação do século XX. Note que a região dos Andes foi removida devido à presença dos Andes. No caso, o coeficiente de correlação é estatisticamente significativo ao nível de $5 \%$ para todo o domínio. 


\subsection{O Clima no cenário $2 \times \mathrm{CO}$.}

A diferença entre a mediana da precipitação total durante a estação chuvosa simulada para o cenário $2 \mathrm{xCO} 2$ e a simulada para o cenário do século XX está representada na fig. 8. Sobre a região do cerrado brasileiro esta diferença é pequena, sendo que a simulação para o cenário $2 \mathrm{CO} 2$ não apresenta mudança significativa na posição central (mediana) de sua distribuição de freqüência em relação à simulação para o cenário do século XX (Fig. 8). É importante ressaltar que o modelo MIROC indica um aumento da precipitação durante a estação chuvosa sobre o oeste da Amazônia e sobre o norte da região Nordeste do Brasil, que apresenta diferenças entre 40 e $80 \mathrm{~mm}$ na mediana da precipitação total sazonal, ao nível de significância de $5 \%$ (Fig. 8).

Em todo o domínio observado, não há mudança estatisticamente significativa nas medianas de início da estação chuvosa entre a simulação para o cenário futuro e a simulação para o cenário do século XX (Fig. 9). Sobre a região do Brasil central, as diferenças entre as medianas dos dois conjuntos de dados ficam em torno de zero e inferiores a duas pêntadas. Comportamento semelhante é observado para a mediana de duração da estação chuvosa (Fig. 10). A diferença entre a simulação do MIROC para o cenário 2xCO2 e para o cenário do século XX da mediana de duração da estação chuvosa fica entre zero e uma pêntada na região do cerrado. (Fig. 10).

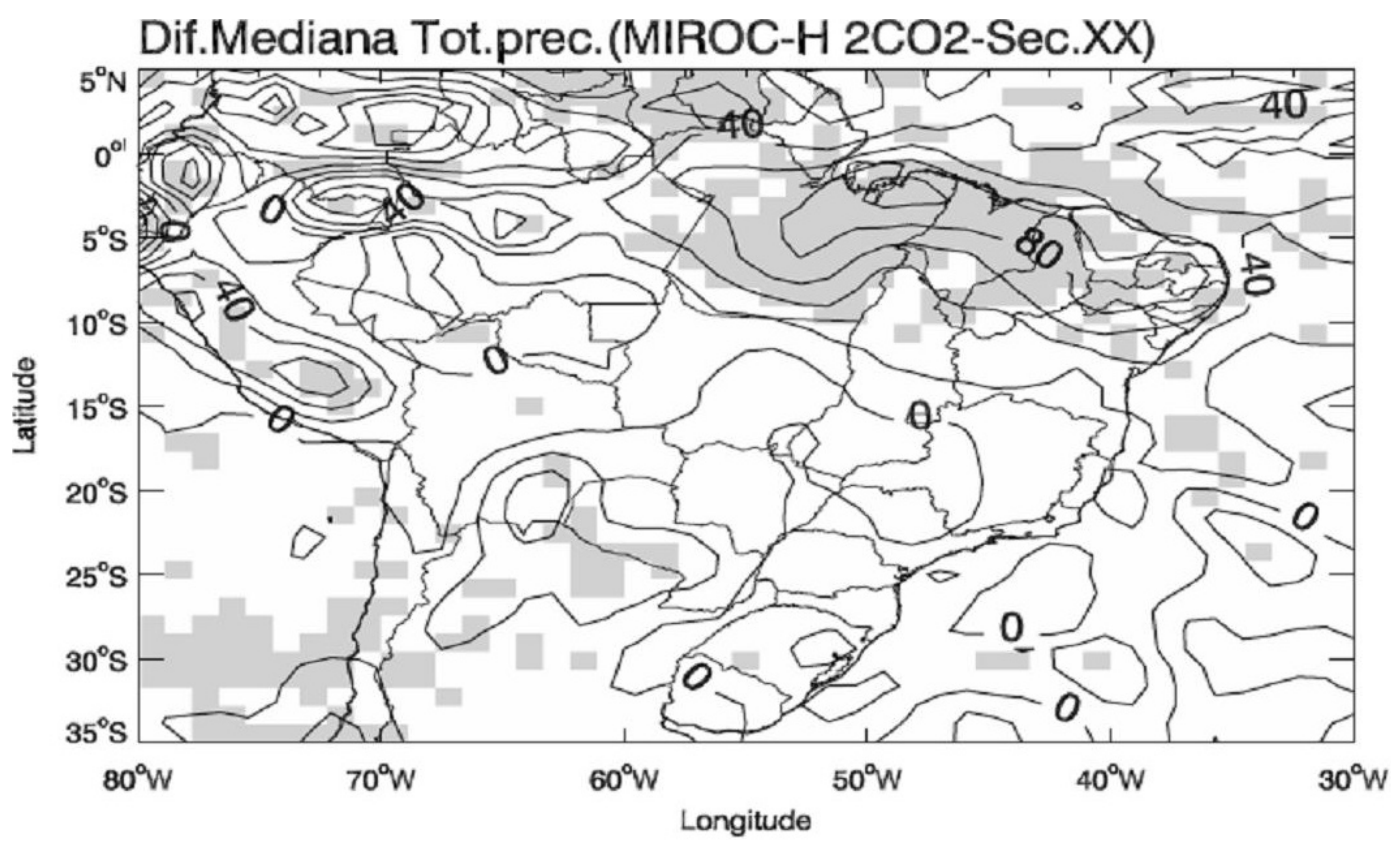

Figura 8 - Diferença entre a mediana do total precipitado durante a estação chuvosa simulada pelo MIROC para o cenário $2 \mathrm{CO} 2$ e para o cenário do século XX, onde as isolinhas estão separadas por um intervalo de $20 \mathrm{~mm}$ e as regiões sombreadas mostram as regiões onde a diferença é estatisticamente significativa para o teste da mediana, ao nível de significância de $5 \%$.

\subsection{Variabilidade da estação chuvosa sobre o cerrado}

O propósito desta análise é examinar as características da estação chuvosa obtidas por integrações do modelo MIROC, com foco particular na região do cerrado. Para este propósito, foram examinadas as sub-regiões localizadas no domínio do modelo entre 22,99S - 12,9S e 48,38W - 51,75W. Este domínio está subdividido em duas sub-regiões que serão tratadas distintamente: SE e CO, conforme indicado na Fig.1 e discutido no item 2.1. Os pontos de grade que ficam na fronteira entre as duas regiões foram eliminados para não interferir no estudo estatístico.
A figura 11 mostra o ciclo anual médio da precipitação para as sub-regiões SE (Fig. 11a) e CO (Fig. 11b). O ciclo anual médio da precipitação é bem semelhante ao observado para ambas as regiões tanto na simulação do século XX como na simulação de 2xCO2 (Fig. 11a,b), sendo a precipitação ligeiramente subestimada durante o inverno (por volta das pêntadas 20 a 55) para as duas simulações de ambas as regiões (Fig. 11a,b), consistente com Vera et al, 2006. Sobre o CO (Fig. 11b), o ciclo anual médio é superestimado pelo modelo durante o verão (por volta das pêntadas 69 a 73 e 1 a 12) em ambos os cenários.

Com a precipitação total durante a estação chuvosa tanto dos dados originais como dos resultados do modelo, 
construiu-se a distribuição de freqüência destes resultados para o SE e para o CO, utilizando-se conjuntamente todos os dados de cada ponto de grade para cada região (Figs. 12 a 14). Para o cenário do século $\mathrm{XX}$, a distribuição da chuva na região SE é bastante semelhante ao obtido com o GPCP (Fig. 13a), sendo estatisticamente semelhantes em relação à posição central (mediana) ao nível de significância de $5 \%$. Nota-se, entretanto, que os valores medianos e acima destes são superestimados pelo MIROC em relação aos dados do GPCP (Figs. 12a e 13a) com diferença de $5,7 \%$ para o percentil de $75 \%$ (Figs. 12a e $13 \mathrm{a}$ ).

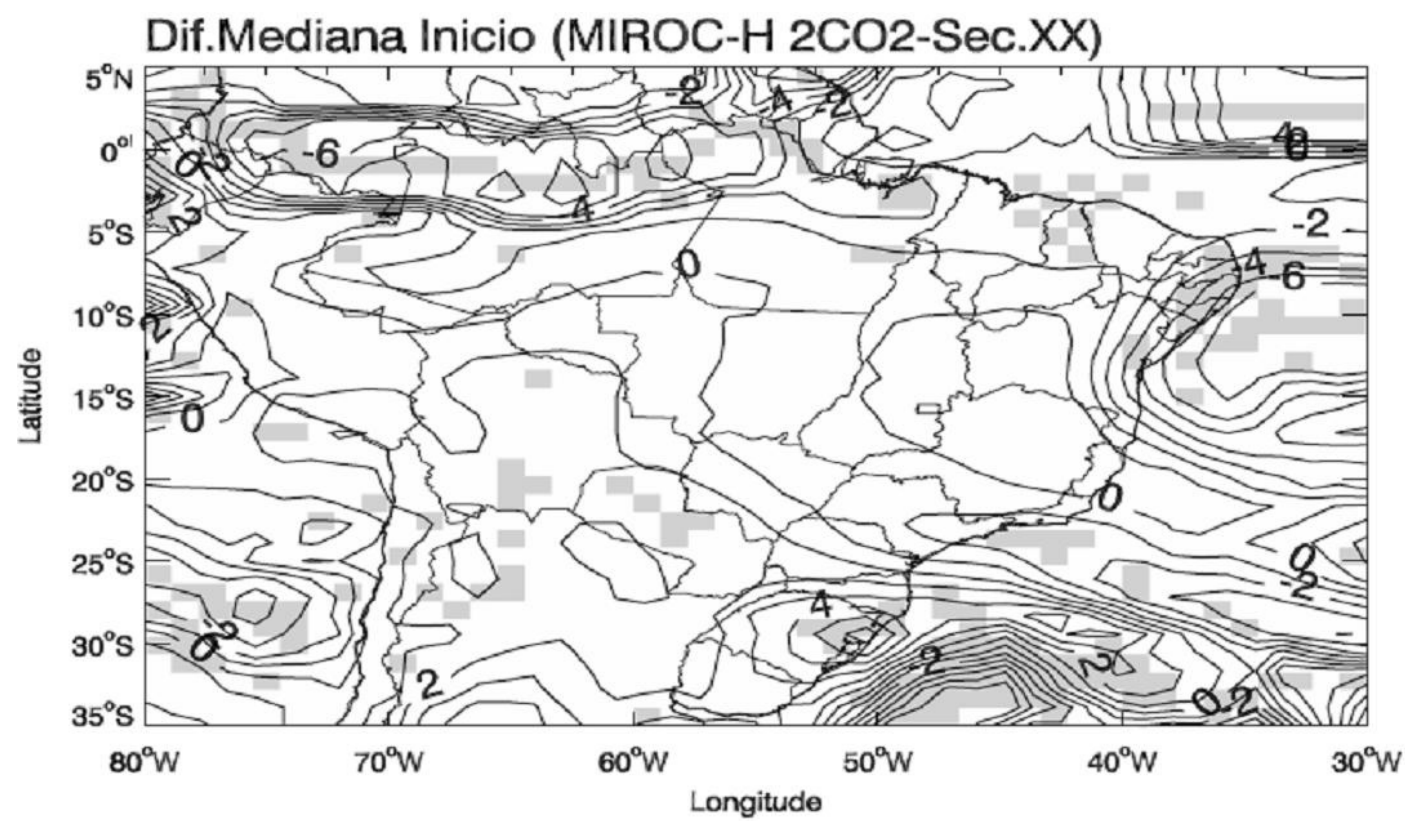

Figura 9 - Diferença entre a mediana do início da estação chuvosa simulada pelo MIROC para o cenário 2 CO2 e para o cenário do século XX, onde as isolinhas estão separadas por um intervalo de 1 pêntada e as regiões sombreadas mostram as regiões onde a diferença é estatisticamente significativa para o teste da mediana, ao nível de significância de $5 \%$.

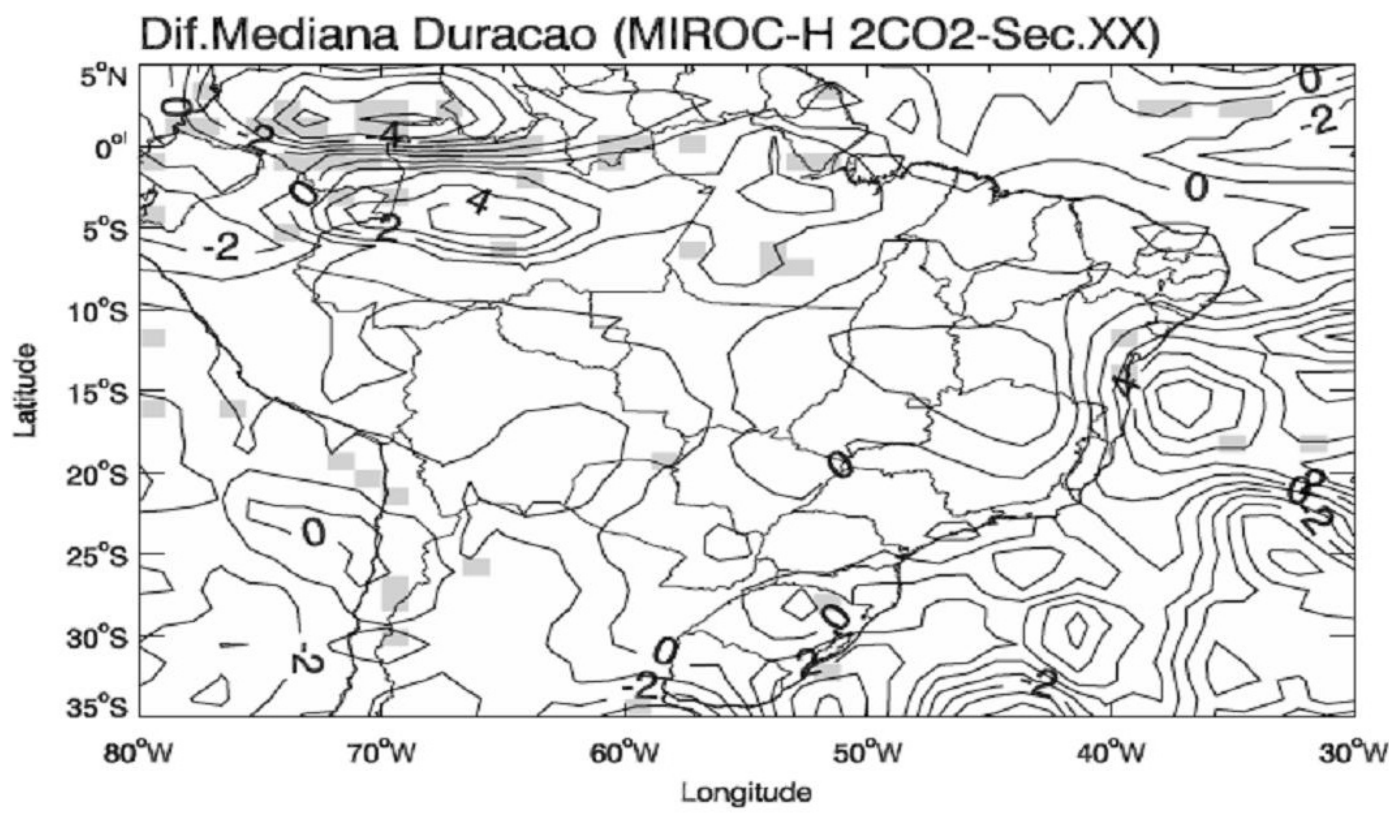

Figura 10 - Diferença entre a mediana da duração da estação chuvosa simulada pelo MIROC para o cenário 2 CO2 e para o cenário do século XX, onde as isolinhas estão separadas por um intervalo de 1 pêntada e as regiões sombreadas mostram as regiões onde a diferença é estatisticamente significativa para o teste da mediana, ao nível de significância de $5 \%$. 
A região CO apresenta uma distribuição comparativamente mais diferenciada com respeito às observações com o GPCP. Por exemplo, a diferença para o percentil de $25 \%$ entre as duas observações é de aproximadamente $+15,0 \%$. Além disso, a distribuição para o CO é estatisticamente diferente em relação

Ciclo Medio Anual

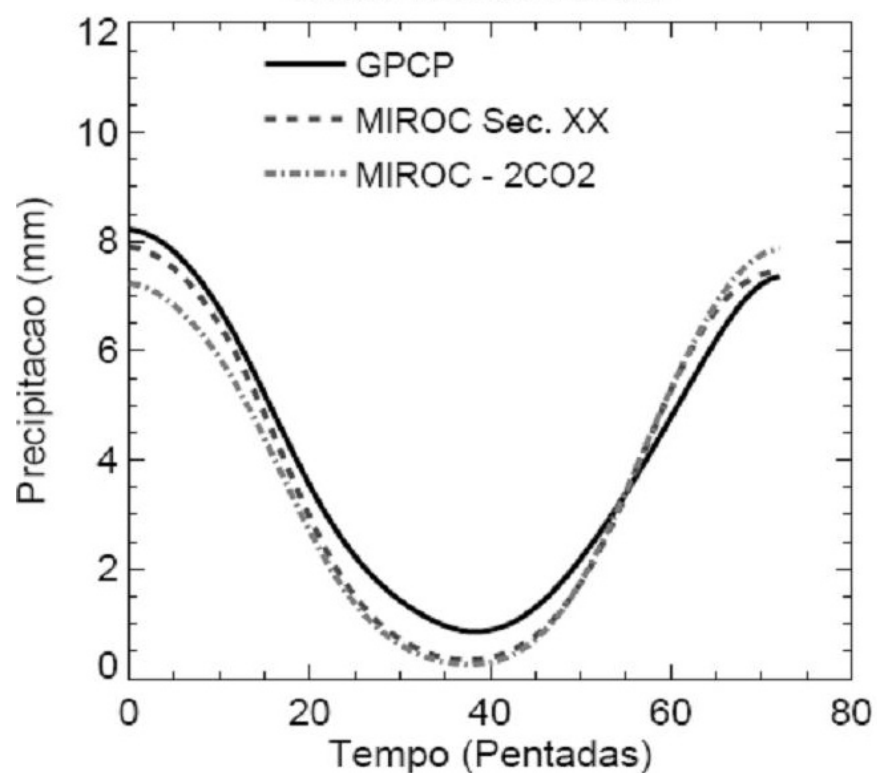

a) à mediana ao nível de $5 \%$, apresentando $11,8 \%$ de diferença em relação ao GPCP (Figs. 12b e 13b). Estes resultados indicam que o MIROC representa de forma mais adequada as características da precipitação sazonal do verão sobre o SE, mas superestima a mesma sobre o CO.

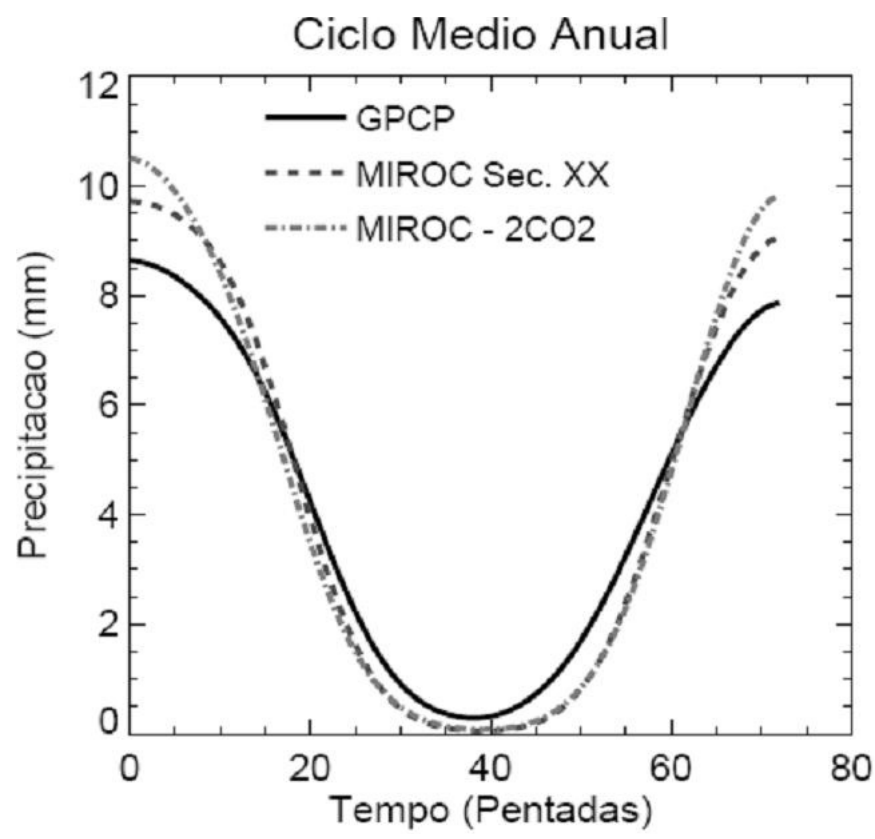

b)

Figura 11 - Ciclo anual médio dos dados do GPCP, modelo MIROC para o cenário do século XX e modelo MIROC para o cenário 2xCO2, para a região do (a) SE; (b) CO.
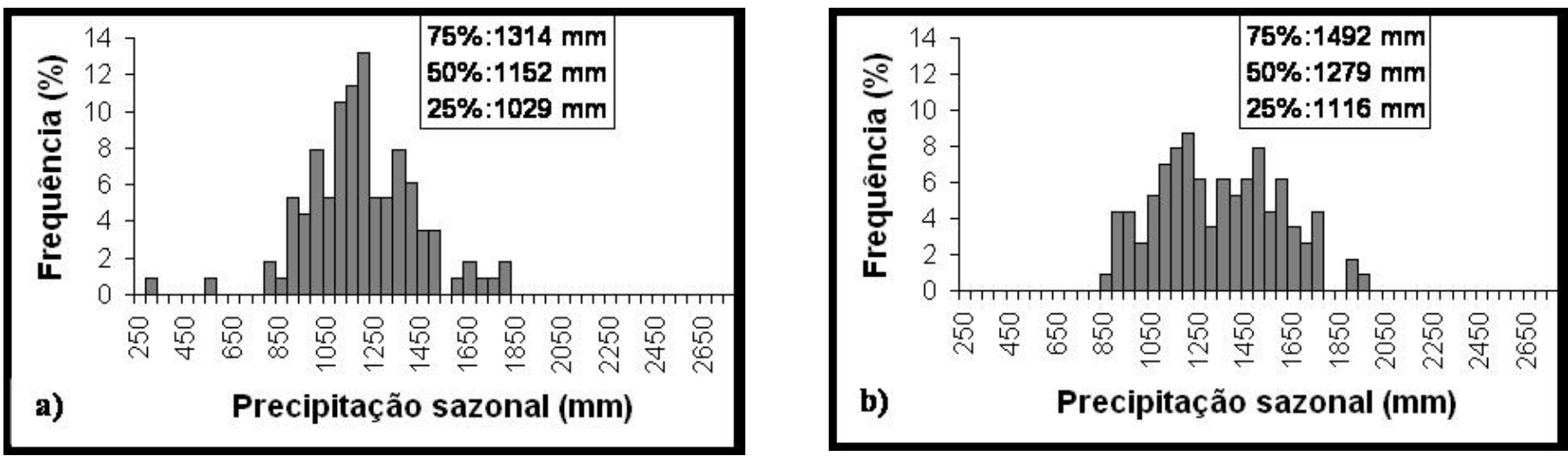

Figura 12 - Distribuição de freqüência da precipitação total durante a estação chuvosa, dos dados do GPCP, para a região do (a) SE e (b) CO. Os percentis de $25 \%, 50 \%$ e $75 \%$ estão indicados na figura.

A Fig. 14 mostra os resultados do total precipitado dentro da estação chuvosa no cenário $2 \mathrm{xCO} 2$. A distribuição da precipitação total durante a estação chuvosa para a região SE apresenta diferenças em relação aos dados da simulação para o cenário do século XX de $-4,3 \%$ para o percentil de $75 \%$ e de
$-0,8 \%$ para o percentil de $25 \%$ (Fig. 14a), sendo que as duas distribuições são estatisticamente semelhantes em relação à mediana ao nível de significância de $5 \%$. Já para o CO, as caudas da distribuição se alongam, tanto para os altos quanto para os baixos valores de precipitação, indicando grande variabilidade 
dos totais nesta região (Fig. 14b). As diferenças em relação aos dados da simulação para o cenário do século XX chegam até $5,5 \%$ para o percentil de $75 \%$ e $-9,4 \%$ para o percentil de $25 \%$. Porém, estas distribuições são semelhantes em relação à posição central.

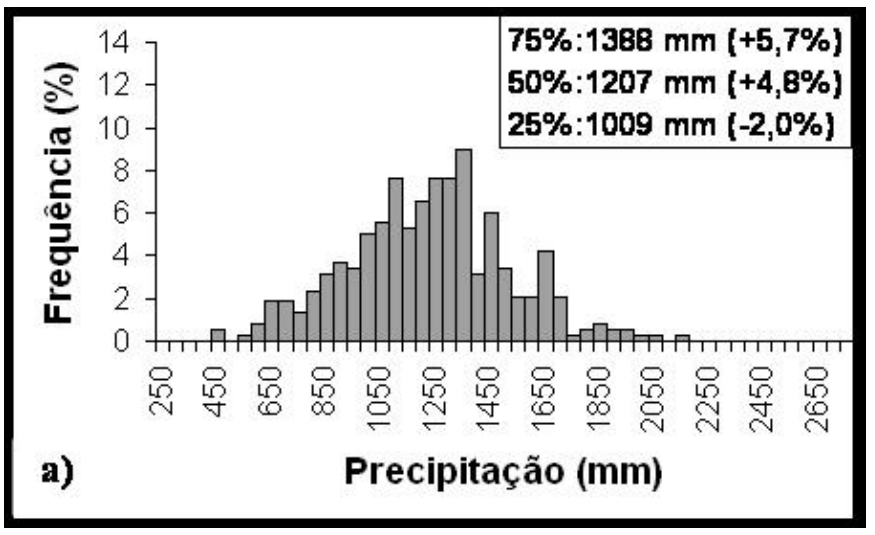

Os resultados indicam que o modelo simula uma mudança na ocorrência de extremos sobre o SE e CO com diminuição de extremos sobre o SE e aumento de extremos sobre a região $\mathrm{CO}$, o que significa um aumento tanto de anos mais chuvosos como de anos mais secos.

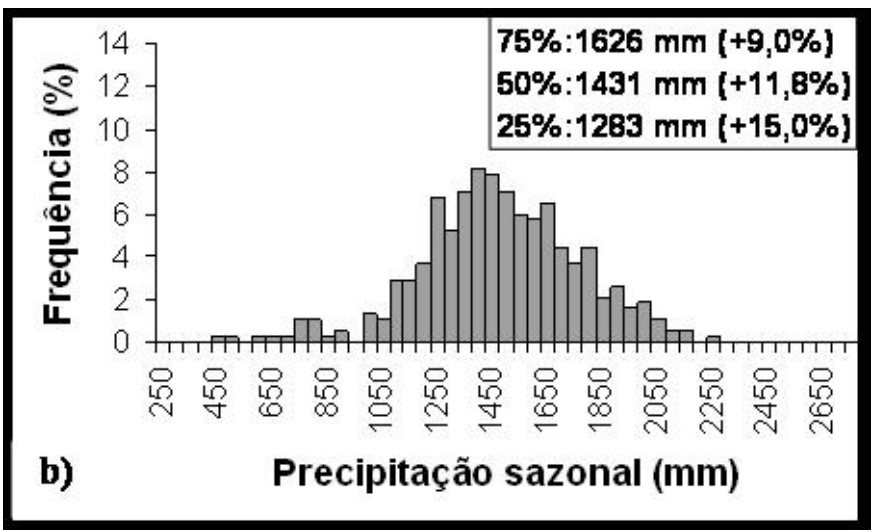

Figura 13 - Distribuição de freqüência da precipitação total durante a estação chuvosa, dos dados do modelo na rodada do século XX, para a região do (a) SE e (b) CO. A figura apresenta os percentis da distribuição e a diferença destes em relação à distribuição do GPCP.
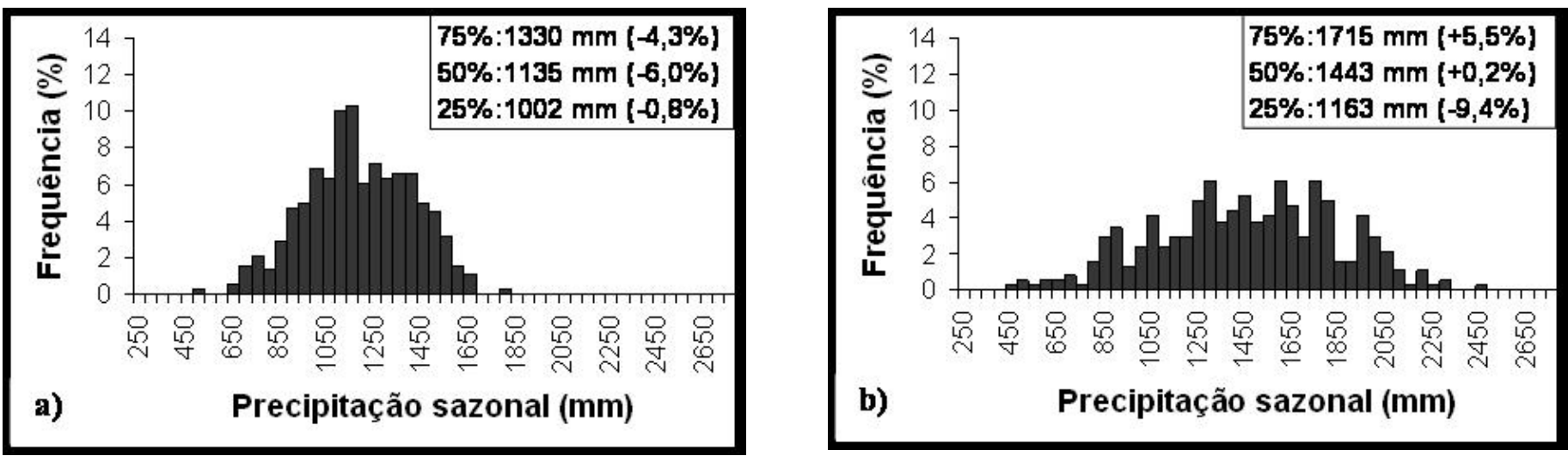

Figura 14 - Distribuição de freqüência da precipitação total durante a estação chuvosa, dos dados do modelo para o cenário 2xCO2, para a região do (a) SE e (b) CO. A figura apresenta os percentis da distribuição e a diferença destes em relação à distribuição do MIROC (Sec. XX).

\section{CONCLUSÃO}

Neste estudo foram verificadas as características da estação chuvosa tais como início, duração e total precipitado nos dados do GPCP e no modelo MIROC para o clima do século XX e um cenário com duas vezes a concentração atual do CO2. Utilizaram-se as simulações totalmente acopladas (fully coupled) tanto para o clima do século XX quanto para o clima no cenário $2 \mathrm{xCO} 2$. O método para a determinação das monções de verão empregado no presente estudo (Liebmann e Marengo, 2001) utiliza apenas as séries de precipitação e é bastante eficiente em caracterizar o período em que as chuvas tornam-se mais regulares.
Sobre a região do cerrado, a mediana da precipitação durante a estação chuvosa encontra-se entre 1000 e 1400 mm. A estação chuvosa o sobre esta região mostra medianas de início entre o começo de outubro e começo de novembro e duração de 32 a 36 pêntadas. A correlação entre a duração da estação e a precipitação durante a estação chuvosa é alta para todo o domínio estudado, apresentando os menores valores na região do cerrado, entre 0,85 e 0,75 , o que pode ser indicativo da variabilidade intra-sazonal da precipitação dentro da estação chuvosa.

O modelo MIROC, de maneira geral, consegue uma boa representação do início, duração e total precipitado dentro da estação chuvosa para a região que engloba o Mato Grosso, 
o Mato Grosso do Sul, São Paulo, Minas Gerais e Goiás, apresentando semelhança ao observado na maior parte desta região, estatisticamente significativa ao nível de significância de $5 \%$. As diferenças em relação aos dados do GPCP para esta região ficam, em geral, por volta de duas pêntadas para o início e duração da estação chuvosa e em até $20 \mathrm{~mm}$ para o total precipitado e a duração da estação chuvosa é subestimada em até duas pêntadas sobre o noroeste do Mato Grosso, Tocantins e sul do Pará. Entretanto, é importante ressaltar que a representação do total precipitado dentro da estação chuvosa é subestimada em mais $120 \mathrm{~mm}$ na região da foz do rio Amazonas e superestimada em aproximadamente $40 \mathrm{~mm}$ no norte do Nordeste brasileiro. Além disso, o início da estação chuvosa é subestimado em mais de seis pêntadas sobre o extremo norte da Amazônia, região Nordeste do Brasil e extremo sul do país e superestimado em mais de seis pêntadas no sobre a região da foz do rio Amazonas e o oeste da Amazônia.

Para um cenário com o dobro da concentração atual de $\mathrm{CO} 2$ na atmosfera, o modelo MIROC não apresenta diferenças estatisticamente significativas do início e duração da estação chuvosa em relação à simulação do século XX em todo o domínio brasileiro. Entretanto, há um aumento significativo da mediana do total acumulado de precipitação durante a estação chuvosa de aproximadamente $80 \mathrm{~mm}$ sobre uma larga faixa sobre o oeste da Amazônia, foz do rio Amazonas e norte da região Nordeste do Brasil, indicando que um cenário de aumento de temperatura global por incremento de $\mathrm{CO} 2$ na atmosfera pode levar a um aumento da concentração das chuvas na estação chuvosa na região. Nas demais áreas do país as diferenças entre o total precipitado para o cenário $2 \mathrm{xCO} 2$ e o cenário do século XX ficam em torno de $20 \mathrm{~mm}$. As diferenças em relação à simulação para o século XX ficam em torno de 0 (zero) até duas pêntadas para o início da estação chuvosa e por volta de 0 (zero) para a duração na maior parte do Brasil.

Sobre o cerrado, o modelo tende a superestimar o total precipitado durante a estação chuvosa para o clima do século XX. Apesar disso, representa muito bem o ciclo anual médio das regiões $\mathrm{SE}$ e $\mathrm{CO}$ e simula bem a distribuição de freqüência do total precipitado durante a estação chuvosa para a região SE em relação à posição central, ao nível de significância de 5 \%. Já para a região $\mathrm{CO}$, esta distribuição não é tão bem representada. Para o cenário $2 \mathrm{xCO} 2$, a distribuição de freqüência do total precipitado durante a estação chuvosa concentra-se sobre o valor central para a região $\mathrm{SE}$ e indica uma diminuição na ocorrência de extremos sobre a região. Já para a região $\mathrm{CO}$, há uma assimetria ainda maior nas caudas da distribuição, o que sugere um possível aumento na ocorrência tanto de anos mais chuvosos quanto de anos mais secos.

O presente estudo mostrou a complexidade envolvida na identificação das características da estação chuvosa sobre o
Brasil. Os resultados apresentados apontam para a necessidade de examinar em detalhes o comportamento do sistema monçônico e respectivas implicações remotas e locais, de modo a compreender possíveis impactos causados por mudanças climáticas globais. Embora tenham sido analisadas apenas as simulações de um único modelo, os resultados aqui discutidos indicam que metodologia apresentada pode ser expandida para avaliar as características da estação chuvosa em outros modelos globais ou experimentos com distintas características de simulação.

\section{AGRADECIMENTOS}

Os autores agradecem o Dr. Humberto R. Rocha por seus importantes comentários e sugestões. R. J. Bombardi agradece o apoio financeiro do Conselho Nacional de Desenvolvimento Cientifico e Tecnológico - CNPq (Processo: 111949/2004-1) e da Fundação de Amparo à Pesquisa do Estado de São Paulo - FAPESP (Processo: 06/53769-6).

Os autores agradecem o apoio financeiro da FAPESP (Proc: 02/09289-9). L. M. V. Carvalho agradece o CNPq (Proc: 474033/2004-0)

\section{REFERÊNCIAS}

ARAKAWA, A.; W. H. SCHUBERT, Interactions of cumulus cloud ensemble with the large-scale environment. Part I. J. Atmos. Sci., v. 31, p. 671-701, 1974.

CARVALHO, L.M.V.; C. JONES; B. LIEBMANN. Extreme precipitation events in southeastern South America and large-scale convective patterns in the South Atlantic convergence zone. J. Climate, v. 15, p. 2377-2394, 2002.

CARVALHO, L.M.V.; C. JONES; B. LIEBMANN. The South Atlantic Convergence Zone: persistence, intensity, form, extreme precipitation and relationships with intraseasonal activity. J. Climate, v. 17, p. 88-108., 2004.

GAN, M. A.; V. E. KOUSKY; C. F. ROPELEWSKI. The South America Monsoon Circulation and Its Relationship to Rainfall over West-Central Brazil. J. Climate, v. 17, p. $47-66,2004$.

GRIMM, A. M.; V. R. BARROS; M. E. DOYLE. Precipitation Anomalies in Southern South America Associated with El Niño and La Niña Events. J. Climate, v. 11, p. 2863-2880, 1998.

GRIMM, A. M.; S. E. T. FERRAZ; J. GOMES. Climate Variability in Southern Brazil Associated with El Niño and La Niña Events. J. Climate, v. 13, p. 35-58, 2000.

HASUMI, H.; S. EMORI. K-1 Coupled GCM (MIROC) Description. Disponível em: $<$ http://www.ccsr.u-tokyo. ac.jp/kyosei/hasumi/MIROC/tech-repo.pdf.>. Acesso em: 20 Set. 2006 
IPCC, 2001. Climate change 2001. Impacts, Adaptation, and Vulnerability - Contribution of Working Group II to the Third Assessment Report of the Intergovernmental Panel on Climate Change, editores J.J. MCCARTHY; O.F. CANZIANI; N.A. LEARY; D.J. DOKKEN; K.S. WHITE; Cambridge University Press, Cambridge, UK e New York, N.Y.,USA.

LE TREUT, H.; Z.-X. LI, Sensitivity of an atmospheric general circulation model to prescribed SST changes: feedback effects associated with the simulation of cloud optical properties, Climate Dynamics, v. 5, p. 175-187, 1991.

LIN J. L.; G. N. KILADIS; B. E. MAPES; K. M. WEICKMANN; K. R. SPERBER; W. LIN; M. C. WHEELER; S. D. SCHUBERT; A. Del GENIO; L. J. DONNER; S. EMORI; J. F. GUEREMY; F. HOURDIN; P. J. RASCH; E. ROECKNER; J F. SCINOCCA. Tropical Intraseasonal Variability in 14 IPCC AR4 Climate Models. Part I: Convective Signals. J. of Climate, v. 19, p. 2665-2690. 2006.

JONES, C.; CARVALHO L.M.V. Active and Break phases in the South American Monsoon System. J. Climate, v. 15, p. 905-914. 2002.

KAYANO, M. T.; V. E. KOUSKY. Sobre o monitoramento das oscilações intrasazonais. Rev. Bras. Meteor., v. 7, p. 593-602. 1992.

KOUSKY, V. E. Pentad outgoing longwave radiation climatology for the South American sector. Rev. Bras. Meteor., v. 3, p. 217 - 231. 1988.

LENTERS, J.D.; K.H. COOK. Summertime precipitation variability over South America: Role of the large-scale circulation. Mon. Wea. Rev., v. 127, p. 409-431. 1999.

LIEBMANN, B.; J. MARENGO. Interannual variability of the rainy season and rainfall in the Brazilian Amazon Basin. J. Climate, v. 14, p. 4308-4318. 2001.

LINCOLN M. A.; J. A. MARENGO; H. CAMARGO; E C. CASTRO, Início da Estação Chuvosa na Região Sudeste do Brasil Parte 1 - Estudos Observacionais. Rev. Bras. Metor., v. 20, n. 3, p. 385-394, 2005.

MARENGO, J. A.; B. LIEBMANN; V. E. KOUSKY; N. P. FILIZOLA; I. C. WAINER. Onset and end of the rainy season in the Brazilian Amazon basin. J. Climate, v. 14, p. 833 - 852. 2001.

MARENGO, J. A.; I. F. A. CAVALCANTI; P. SATYAMURTY; I. TROSNIKOV; C. A. NOBRE; J. P. BONATTI; H. CAMARGO; G. SAMPAIO; M. B. SANCHES; A. O. MANZI; C. A. C. CASTRO; C. D’ALMEIDA; L. P. PEZZI; L. CANDIDO. Assessment of regional seasonal rainfall predictability using the CPTEC/COLA atmospheric GCM. Clim. Dym., v. 21, p. $459-475,2003$.
MARRIS, E. The Forgotten Ecosystem. Nature, v. 437, p. 944 $-945.2005$

MCFARLANE, N. A. The effect of orographically excited gravity wave drag on the general circulation of the lower stratosphere and troposphere. J. Atmos. Sci., v. 44, p. 1775-1800, 1987.

MEEHL, G. A.; J. M. ARBLASTER; C. TEBALDi. Understanding future patterns of increased precipitation intensity in climate model simulations. Geophys. Res. Lett., v. 32, L18719, doi:10.1029/2005GL023680, 2005

MELLOR, G. L.; T. YAMADA, Development of a turbulence closure model for geostrophic fluid problems, Rev. Geophys., v. 20, p. 851-875, 1982.

MELLOR, G. L.; L. KANTHA, An ice-ocean coupled model, J. Geophys. Res., v. 94, p. 10,937-10,954, 1989.

Model Information of Potential Use to the IPCC Lead Authors and the AR4 <http://www-pcmdi.llnl.gov/ipcc/model_ documentation/MIROC3.2_hires.htm> Acesso em: 17 Fev. 2007

NAKAJIMA, T.; M. TSUKAMOTO; Y. TSUSHIMA; A. NUMAGUTI; T. KIMURA, Modeling of the radiative process in an atmospheric general circulation model, Appl. Opt., v. 39, p. 4869-4878, 2000.

RAO, V.B.; M. LIMA; S.H. FRANCHITO. Seasonal and Interannual Variations of Rainfall over Eastern Northeast Brazil. J. Climate, v. 6, p. 1754-1763, 1993.

VERA, C.; W. HIGGINS; T. AMBRIZZI; J. AMADOR; R. GARREAUD; D. GOCHIS; D. GUTZLER; D. LETTENMAIER; J. MARENGO; C. R. MECHOSO; NOGUES-PAEGLE; P. L. SILVA DIAS; C. ZHANG. Toward a Unified View of the American Monsoon Systems. J. Climate, v. 19, p. 4977-5000, 2006.

VERA, C.; G. SILVESTRI; B. LIEBMANN; P. GONZÁLEZ. Climate change scenarios for seasonal precipitation in South America from IPCC-AR4 models. Geophys. Res. Lett., v. 33, L13707, doi:10.1029/2006GL025759, 2006

WILKS, D. S. Statistical methods in the Atmospheric Sciences. Academic Press: New York, second edition, 2006, 627 p.

XIE, P.; J.E. JANOWIAK; P.A. ARKIN; R. ADLER; A. GRUBER; R. FERRARO; G.H. HUFFMAN; S. CURTIS. GPCP Pentad Precipitation Analyses: An Experimental Dataset Based on Gauge Observations and Satellite Estimates. J. Climate, v. 16, p. 2197-2214. 2003.

YAMAZAKI, Y.; V. B. RAO. Tropical cloudiness over the South Atlantic Ocean. J. Meteor. Soc. Japan, v. 55, p. $205-$ 207, 1977.

ZHOU, J.; K. M. LAU. Does a Monsoon Climate Exist over South America? Journal of Climate, v.11, p. 1020 - 1040, 1998. 